\title{
Colorectal cancer screening: strategies to select populations with moderate risk for disease
}

\author{
M. Navarro, ${ }^{1,2}$, G. Binefa ${ }^{1,2}$, I. Blanco ${ }^{1,2}$, J. Guardiola ${ }^{3}$, F. Rodríguez-Moranta ${ }^{3}$, M. Peris ${ }^{1,2}$; and the Catalan \\ Colorectal Cancer Screening Pilot Programme Group*
}

${ }^{\prime}$ Cancer Prevention and Control Unit. Catalan Institute of Oncology. L'Hospitalet de Llobregat, Barcelona. Spain. ${ }^{2}$ Bellvitge Institute for Biomedical Research (IDIBELL). L'Hospitalet de Llobregat, Barcelona. Spain . ${ }^{3}$ Digestive Endoscopy Unit. Gastroenterology Department. University Hospital of Bellvitge. Barcelona, Spain

\begin{abstract}
Objective: to analyse the association between rectal bleeding or a family history of colorectal cancer $(\mathrm{CRC})$ and the results obtained in two rounds of a CRC screening pilot programme performed in L'Hospitalet, Barcelona, Spain.

Subjects: males and females (50-69 years) were the target population. Together with the invitation letter, they received a questionnaire in which they were asked about rectal bleeding, family history of CRC and related neoplasms. The screening test was a guaiac-based faecal occult blood test (FOBT), and colonoscopy for positive tests.

Results: 25,829 FOBT were performed in 18,405 individuals. Information on rectal bleeding and a family history of CRC were obtained for 9,849 and 9,865 cases, respectively. Male sex $(\mathrm{OR}=1.32), 60-69$ years of age $(\mathrm{OR}=1.48)$, rectal bleeding (OR $=1.84)$ and history of CRC (OR $=1.54)$ were independent predictors of positive FOBT. With regard to colonoscopy, a greater risk of diagnosing advanced neoplasm was observed among men $(\mathrm{OR}=2.47)$ and subjects with a family history of CRC $(\mathrm{OR}=$ 1.98).

Conclusions: $\mathrm{CRC}$ screening programmes must have instruments that make it possible to select the candidate population and the possibility of offering a study suited to the risk of individuals who are not susceptible to population screening by means of FOBT.
\end{abstract}

Key words: Colorectal cancer screening. Fecal occult blood test. Rectal bleeding. Family history of CRC. Risk assessment.

\footnotetext{
*The Catalan Colorectal Cancer Pilot Screening Programme Group are: M. Peris, G. Binefa, M. Navarro, J. A. Espinàs, J. M. Borràs, I. Blanco, A. Clopes, V. Moreno, G. Capellá (Catalan Institute of Oncology). J. M. Miquel, J. M. Nogueira, G. García Mora, J. Martí-Ragué, X. Sanjuán (University Hospital of Bellvitge). S. Calero (Catalan Institute of Health, Primary Health Care Division).
}

Received: $18-05-09$.

Accepted: 10-07-09.

Correspondence: Gemma Binefa. Cancer Prevention and Control Unit. Catalan Institute of Oncology. Av. Gran Via de l'Hospitalet, 199-203. 08907 Hospitalet de Llobregat. Barcelona, Spain.e-mail: gbinefa@iconcologia.net
Navarro M, Binefa G, Blanco I, Guardiola J, Rodríguez-Moranta F, Peris M; and the Catalan Colorectal Cancer Screening Pilot Program Group. Colorectal cancer screening: strategies to select populations with moderate risk for disease. Rev Esp Enferm Dig 2009; 101: 855-860.

\section{INTRODUCTION}

Early diagnosis in colorectal cancer (CRC) remains crucial to the outcome of surgery, which is the cornerstone option for cure. The incidence and mortality of CRC in the European Union is considered so disturbing that the European Union Commissioner on Health has recommended screening programmes with faecal occult blood test (FOBT) to be considered in all member states (1).

Population screening programmes target individuals above 50 years old without additional risk factors (symptoms suggestive of the existence of CRC, chronic inflammatory disease, personal history of adenomas, CRC or family risk of CRC) (2-4). Clinical guidelines exist for screening high-risk patients, including those with a history of familial polyposis or hereditary non-polyposis colorectal cancer $(5,6)$. The possibility of investigating whether the individuals to be screened have additional risk factors constitutes an added difficulty in the context of screening programmes on large populations due to the significant cost entailed by carrying out exhaustive medical histories in participating subjects who may be suspected to belong to higher-risk groups.

We present the prospective results of the questionnaire included in the first two rounds performed in a pilot CRC screening programme based on FOBT performed in L'Hospitalet, Barcelona. The study endpoint is to evaluate the efficacy of this questionnaire by analysing screening results and the presence of rectal bleeding or family 
history of colorectal cancer in the participating population in the two rounds performed.

\section{METHODS}

The CRC pilot screening programme was directed at the 50-to-69-year-old population in L'Hospitalet, a city of 239,000 inhabitants in the metropolitan area of Barcelona (Catalonia), Spain. Demographic data on this population was gathered from the Primary Healthcare Information System. A hospital cancer registry covering the city was linked to exclude subjects with a diagnosis of colorectal cancer. Two screening rounds were successively performed. The first round involved 11,011 of the 63,880 people invited to participate. The second round involved 14,818 of the 66,534 people invited (7).

The population regarded as subject to screening were sent a letter inviting them to participate in the programme, including information on the prevention of CRC and a questionnaire in which they were asked about any episodes of rectal bleeding, previous diagnosis of haemorrhoids, adenomas, colorectal cancer or inflammatory bowel disease, having had a colonoscopy in the previous 5 years, as well as the existence of a family member with CRC or other neoplasms associated with CRC (endometrial and kidney). The questionnaire was sent to the whole target population in the first round, and to the new subjects invited to take part in the second round. Since in some cases the participants returned the questionnaire unanswered, the requested information is not available for all of them.

All subjects with CRC, adenomas or chronic inflammatory bowel disease were definitely excluded from the screening program. Subjects with a previous colonoscopic examination were considered candidates for screening after 5 years of colonoscopy.

When the questionnaire reported two or more relatives with cancer, they were phoned through the programme to check the information and evaluate whether the subject was eligible for population screening with FOBT or met the criteria for hereditary colorectal cancer $(5,6)$. If a high risk family history was confirmed, the subject was excluded from the programme and was offered to be counselled for a more detailed assessment. The programme allowed the screening of subjects with a family history of CRC or other non-colonic neoplasms as long as they did not meet the criteria for hereditary cancer. Rectal bleeding was not considered an exclusion criterion.

The screening test was a guaiac-based faecal occult blood test every 2 years. Participants were asked to collect two stool samples from three bowel movements. Dietary restriction was indicated when a repetition of the test was necessary. If 5 or 6 samples were positive at initial testing, or any of the samples under dietary restriction, a colonoscopy with sedation was indicated. Any polyps found were removed and biopsies of any masses were ob- tained. If a patient had more than 1 polyp, the most advanced pathologic lesion was included in the analysis. The histological classification of polyps and cancers was based on World Health Organisation criteria (8). High-risk adenoma (HRA) was defined as adenoma with severe dysplasia, adenoma bigger than $10 \mathrm{~mm}$, more than 2 adenomas, or any adenoma with tubulovillous or villous histology. Carcinoma in situ was classified as HRA. Low-risk adenoma (LRA) was defined as that of smaller size, tubular type and low-grade dysplasia. Advanced neoplasms included invasive cancer or high-risk adenoma.

In the analysis we have taken into account only one FOBT result for each individual. Hence in participants of both rounds with a positive FOBT in the second round we used the results of the questionnaire sent in the first round.

Differences in categorical variables were compared with the Chi-square test. In the multivariate analysis, the association between a positive FOBT or an advanced neoplasm with the presence of rectal bleeding or a family history of colorectal cancer was analysed using logistic regression, adjusting by sex and age. The variables included in the multivariate analysis were sex, age and those with a significant result in the bivariate analysis. The results were expressed as odds ratios (OR) with 95\% confidence intervals $(95 \% \mathrm{CI})$. Differences were considered statistically significant when $p<0.05$. All analyses were performed with the Stata software, version 9.2 (StataCorp, College Station, TX, USA) and SPSS software (version 13.0 for Windows).

\section{RESULTS}

A total of 1,691 individuals were excluded (986 from the first round and 705 from the second round), 592 $(35.0 \%)$ of whom were excluded by means of the assessment of risk factors included in the questionnaires and considered not eligible for population screening: 262 CRCs, 33 inflammatory bowel diseases, 44 previously diagnosed colon adenomas, 243 had undergone colonoscopies in the previous 5 years, and 10 subjects were excluded due to meeting the criteria for hereditary CRC.

Table I describes the data of participants in both rounds. A total of 25,829 FOBTs were performed in 18,405 individuals, 7,424 of whom participated in both rounds. The results of the study have recently been analysed $(7,9)$. The uptake of colonoscopy among subjects with a positive test was 89\% (442/495). Colonoscopy results were: without findings in 229 subjects, 36 invasive cancers, 121 HRA (33.1\% of whom had an in situ carcinoma), 29 LRA and 27 non-neoplastic polyps. Of the 18,405 people screened, 14,740 questionnaires were received with some of the requested data. From these, information was obtained on the presence of blood in faeces and a family history of CRC in 9,849 and in 9,865 cases, respectively. 
Table I. Results of the first and second rounds

\begin{tabular}{lcc}
\hline & $n$ & $\%$ \\
\hline People screened & 18,405 & \\
\hline Sex & & \\
Female & 10,016 & 54.4 \\
Male & 8,389 & 45.6 \\
\hline Age group (years) & & \\
50-59 & 10,201 & 55.4 \\
60-69 & 8,204 & 44.6 \\
\hline FOBT results & & \\
Positive & 495 & 2.7 \\
Negative & 17,304 & 94.0 \\
Not assessable & 606 & 3.3 \\
\hline Colonoscopies & 442 & 89.3 \\
\hline Colonoscopy result & & \\
Normal & 229 & 51.8 \\
Invasive cancer & 36 & 8.1 \\
High risk adenoma & 121 & 27.4 \\
Low risk adenoma & 29 & 6.6 \\
Non-neoplastic polyp & 27 & 6.1 \\
\hline Questionnaires & 14,740 & 80.1 \\
\hline Rectal bleeding & & \\
No & 6,997 & 47.5 \\
Yes & 2,852 & 19.3 \\
Unanswered & 4,891 & 33.2 \\
\hline Family history of CRC & & \\
No & 9,134 & 62.0 \\
Yes & 5,875 \\
Unanswered & 4,711 & 32.4 \\
\hline Haemorrhoids & & 35.6 \\
No & & \\
Yes & & \\
Unanswered & & \\
\hline & & \\
\hline
\end{tabular}

Table II analyses these two factors in greater detail. It can be observed that rectal bleeding was more frequent in participants with a positive result in FOBT (41.8\%), in men $(31.7 \%)$, in the 50 to 59 age group (30.6\%), and in those presenting haemorrhoids $(43.2 \%)$. The cases that most frequently reported the presence of rectal bleeding were those diagnosed with an invasive cancer $(64.3 \%)$; $42.9 \%$ of individuals without neoplasms (cancer or adenomas) on colonoscopy had haemorrhoids. It can also be observed in table II that the presence of a family history was more frequent among positive FOBTs $(11.0 \%)$, in men (7.6\%), and in the 50 to 59-year age group (7.8\%). People with high-risk adenoma detected followed by invasive cancer were those with the highest frequency of family histories of CRC with 15.9 and $13.9 \%$, respectively.

In the bivariate analysis, the positive result of FOBT was statistically significant with the variables studied except for the presence of haemorrhoids (Table III). Significance was maintained in the multivariate model for each one of the variables, so that a positive FOBT was related to the male gender $(\mathrm{OR}=1.32,95 \% \mathrm{CI}, 1.08-1.62)$, belonging to the 60 to 69 -year age group (OR $=1.48,95 \%$ $\mathrm{CI}, 1.21-1.81)$, the presence of rectal bleeding $(\mathrm{OR}=$ $1.84,95 \% \mathrm{CI}, 1.50-2.26)$, and having a family history of CRC $(\mathrm{OR}=1.54,95 \% \mathrm{CI}, 1.11-2.14)$.

Table IV presents the results of the analysis of the association between the diagnosis of advanced neoplasm and the presence of rectal bleeding or family history of CRC. In the bivariate analysis, the diagnosis of advanced neoplasm was significantly associated with the male gender and the presence of a family history. No association was found with the presence of rectal bleeding or haemorrhoids. In the multivariate model, it was observed that

Tabla II. Characteristics of people with rectal bleeding or family history of CRC who answered the questionnaire

\begin{tabular}{|c|c|c|c|c|c|c|c|c|c|c|}
\hline & \multicolumn{4}{|c|}{ Rectal bleeding } & \multicolumn{6}{|c|}{ Family history of CRC } \\
\hline & \multicolumn{2}{|c|}{ No } & \multicolumn{2}{|c|}{ Yes } & \multirow[b]{2}{*}{$p$-value } & \multicolumn{2}{|c|}{ No } & \multicolumn{2}{|c|}{ Yes } & \multirow[b]{2}{*}{$p$-value } \\
\hline & $n$ & $\%$ & $n$ & $\%$ & & $n$ & $\%$ & $n$ & $\%$ & \\
\hline \multicolumn{11}{|l|}{$\overline{\text { FOBT result }}$} \\
\hline Positive & 234 & 58.2 & 168 & 41.8 & \multirow{2}{*}{$<0.001$} & 372 & 89.0 & 46 & 11.0 & \multirow[t]{2}{*}{$<0.00$} \\
\hline Negative & 6,763 & 71.6 & 2,684 & 28.4 & & 8,762 & 92.7 & 685 & 7.3 & \\
\hline \multicolumn{11}{|l|}{$\overline{S e x}$} \\
\hline Female & 3,851 & 73.5 & 1,392 & 26.5 & \multirow[t]{2}{*}{$<0.001$} & 4,863 & 92.7 & 381 & 7.3 & \multirow[t]{2}{*}{0.585} \\
\hline Male & 3,146 & 68.3 & 1,460 & 31.7 & & 4,271 & 92.4 & 350 & 7.6 & \\
\hline \multicolumn{11}{|l|}{ Age group (years) } \\
\hline $50-59$ & 3,877 & 69.4 & 1,705 & 30.6 & \multirow{2}{*}{$<0.001$} & 5,152 & 92.2 & 440 & 7.8 & \multirow[t]{2}{*}{0.051} \\
\hline $60-69$ & 3,120 & 73.1 & 1,147 & 26.9 & & 3,982 & 93.2 & 291 & 6.8 & \\
\hline \multicolumn{11}{|c|}{ Screening-detected lesions } \\
\hline Invasive cancer & 10 & 35.7 & 18 & 64.3 & \multirow[t]{5}{*}{0.016} & 31 & 86.1 & 5 & 13.9 & \multirow[t]{5}{*}{0.669} \\
\hline High risk adenoma ${ }^{1}$ & 61 & 62.9 & 36 & 37.1 & & 90 & 84.1 & 17 & 15.9 & \\
\hline Low risk adenoma & 21 & 80.8 & 5 & 19.2 & & 22 & 88.0 & 3 & 12.0 & \\
\hline Non-neoplasic polyp & 14 & 58.3 & 10 & 41.7 & & 21 & 91.3 & 2 & 8.7 & \\
\hline Without lesions & 108 & 57.1 & 81 & 42.9 & & 174 & 92.1 & 15 & 7.9 & \\
\hline \multicolumn{11}{|l|}{ Haemorrhoids } \\
\hline No & 4,058 & 86.5 & 631 & 13.5 & \multirow[t]{2}{*}{$<0.001$} & 4,344 & 92.6 & 345 & 7.4 & \multirow[t]{2}{*}{0.952} \\
\hline Yes & 2,923 & 56.8 & 2,220 & 43.2 & & 4,761 & 92.6 & 381 & 7.4 & \\
\hline
\end{tabular}

'Carcinomas in situ are included. 
Table III. Analysis of positive FOBT

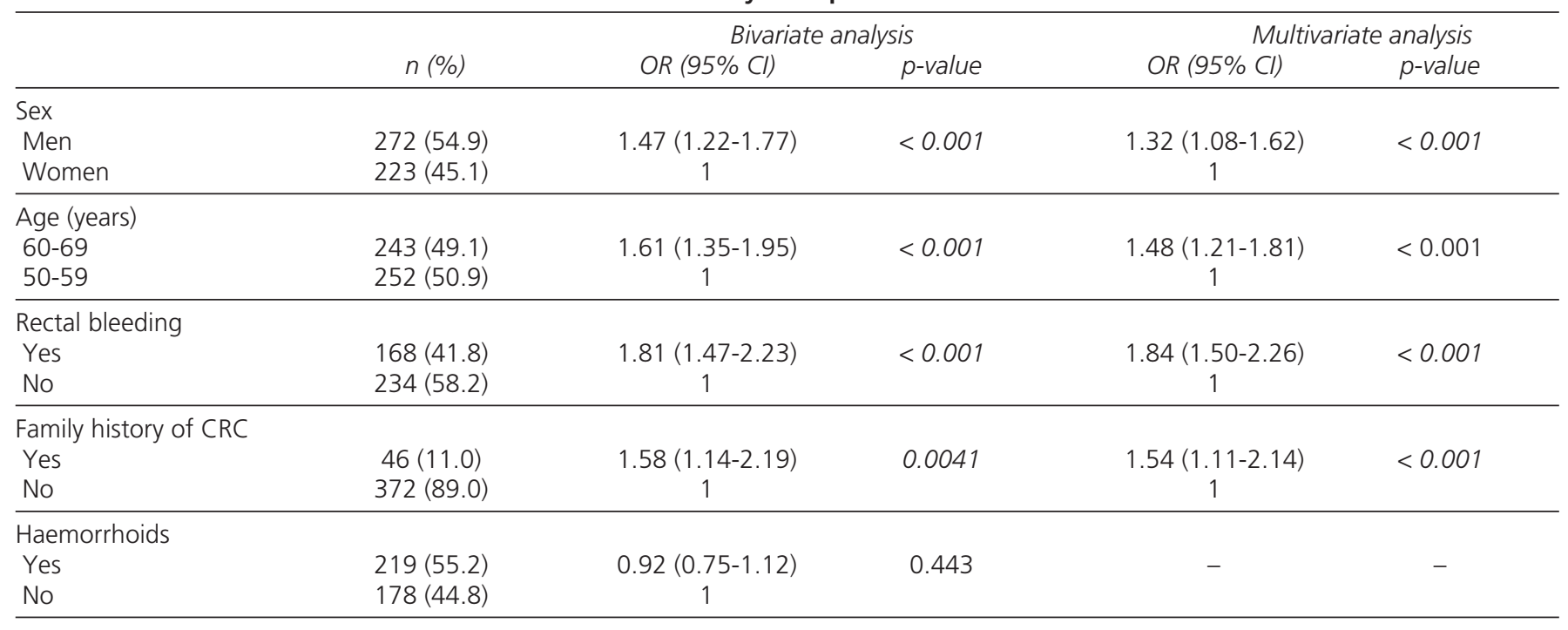

Table IV. Analysis of participants in which screening detected an advanced neoplasm

\begin{tabular}{|c|c|c|c|c|c|}
\hline & \multirow[b]{2}{*}{$n(\%)$} & \multicolumn{2}{|c|}{ Bivariate analysis } & \multicolumn{2}{|c|}{ Multivariate analysis } \\
\hline & & OR $(95 \% \mathrm{Cl})$ & $p$-value & OR $(95 \%$ Cl) & $p$-value \\
\hline \multicolumn{6}{|l|}{ Sex } \\
\hline Men & $106(67.5)$ & $2.41(1.57-3.70)$ & $<0.001$ & $2.47(1.59-3.83)$ & $<0.001$ \\
\hline Women & $51(32.5)$ & 1 & & 1 & \\
\hline \multicolumn{6}{|c|}{ Age (years) } \\
\hline $60-69$ & $79(50.3)$ & $1.14(0.85-1.40)$ & 0.5062 & $1.10(0.72-1.69)$ & 0.650 \\
\hline $50-59$ & $78(49.7)$ & 1 & & 1 & \\
\hline \multicolumn{6}{|c|}{ Rectal bleeding } \\
\hline Yes & $54(43.2)$ & $1.13(0.71-1.80)$ & 0.5767 & - & - \\
\hline No & $71(56.8)$ & 1 & & & \\
\hline \multicolumn{6}{|c|}{ Family history of CRC } \\
\hline Yes & $22(15.4)$ & $1.97(0.99-3.94)$ & 0.0366 & $1.98(1.02-3.84)$ & 0.043 \\
\hline No & $121(84.6)$ & 1 & & 1 & \\
\hline \multicolumn{6}{|c|}{ Haemorrhoids } \\
\hline Yes & $58(50.4)$ & $1.34(0.86-2.10)$ & 0.211 & - & - \\
\hline No & $57(49.6)$ & 1 & & & \\
\hline
\end{tabular}

the risk of presenting an advanced neoplasm was greater among men $(\mathrm{OR}=2.47,95 \% \mathrm{CI}, 1.59-3.83)$ and among people with a family history of $\mathrm{CRC}(\mathrm{OR}=1.98,95 \%$ CI, 1.02-3.84).

\section{DISCUSSION}

Our findings from the two first rounds of the Colorectal Cancer Screening Programme show the higher risk of a diagnosis of advanced colorectal neoplasm among male participants $(\mathrm{OR}=2.47,95 \% \mathrm{CI}, 1.59-3.83)$ and in those with a family history of CRC $(\mathrm{OR}=1.98,95 \% \mathrm{CI}, 1.02$ $3.84)$. The results according to age group and presence of rectal bleeding were not significant.
Currently, there are published guidelines on the different strategies of CRC screening according to the risk in the population $(5,10)$. An annual or biennial FOBT is currently recommended for people above 50 with average risk. A meta-analysis has suggested that the magnitude of the relative reduction in mortality rate by FOBT screening is $16 \%$ overall and $23 \%$ after adjustment for screening attendance (11).

Few data have examined the prevalence of inappropriate CRC screening (12,13). Fisher et al. (13) investigated a sample of 500 consecutive patients who had a FOBT. Overall, $35 \%$ of patients received inappropriate screening, $20 \%$ because of signs or symptoms of gastrointestinal blood loss or a higher-than-average risk of CRC. If we take into account the progressive increase in the screening of the low- 
risk population, it is important to apply the quality measures required to guarantee that the screening is performed in individuals with eligibility criteria. The questionnaires may provide sufficient information to make it possible to detect individuals at higher risk, even although this entails an increase in difficulty and cost when dealing with screening programmes for large populations.

One of the important points to be investigated is if some symptoms may suggest the presence of CRC and because of that a diagnosis procedure should be indicated instead of a population screening. However, it is difficult to diagnose CRC because symptoms may be diffuse $(3,14)$, and associated gastrointestinal distress is frequent in the general population $(15,16)$. Rectal bleeding is a nonspecific symptom and may be due to different conditions, most of them benign, such as haemorrhoids or anal fissures (the most frequent), and also malignant, such as colorectal cancer. Although $40 \%$ of patients with CRC report rectal blood loss, the risk of CRC in a patient with rectal bleeding is low (17-19). On assessing the symptoms, gender and age differences in risk of CRC must be taken into account. In the study of Lawrenson and associates (16) men with symptoms were more likely to be diagnosed with CRC than women.

There are few published studies that investigate the presence of symptoms in the population subjected to screening. Although rectal bleeding is a predictive symptom of colorectal cancer in the population with screening sigmoidoscopy, a majority of cancers and adenomas in this group were detected in individuals who were asymptomatic (20). Ahmed et al. (21) demonstrated, in a CRC screening pilot study, that lower gastrointestinal symptoms are common among individuals who have a positive FOBT. However, symptoms were not related to colonoscopy findings. In our study, approximately $42 \%$ of patients with no findings at colonoscopy or with non-neoplastic polyps reported rectal bleeding. According to the authors, possible explanations for the high prevalence of symptoms may include that these patients respond to screening more than those actually asymptomatic, or else that intestinal symptoms are frequent in the general population. Our data, in agreement with the literature, show that rectal bleeding was present in $43.2 \%$ of those diagnosed with an advanced neoplasm, was more frequent in men than in women, and in people aged between 50 and 59 years more than among those between 60 and 69 years. However, rectal bleeding was not associated with a higher risk of advanced neoplasm $(\mathrm{OR}=1.13,95 \% \mathrm{CI}$, 0.71-1.80). As reported by Ahmed et al. (21), the presence of rectal bleeding alone, as investigated in our screening programme questionnaire, without taking into account the actual characteristics of this or whether there were other symptoms present, may increase the sensitivity of the test without significantly predicting the diagnosis of advanced neoplasm.

Individuals with a family history of CRC have a high risk of developing the disease (5), which increases when it is associated with early age of onset or multiple affect- ed relatives (22-24). Colonoscopy surveillance has been shown to reduce the incidence and mortality of colorectal cancer, not only in families with a history of hereditary nonpolyposis colorectal cancer (HNPCC) $(5,23)$ but also in individuals with a moderate risk due to a family history but not fulfilling any of the Amsterdam or Bethesda criteria (23-25). In families at moderate risk, it is recommended that colonoscopy surveillance be initiated at the age of 45-50 years, since the likelihood of detecting an advanced neoplasm in people under the age of 45 is very small $(23,24,26-28)$. In our study, the presence of a family history of CRC without HNPCC criteria is associated both with a positive result of FOBT and a diagnosis of advanced neoplasm.

Although our results are similar to others already published in the literature $(21-24,28)$, they must be assessed within the context of a prospective study of a questionnaire with some limitations. In the first place, as the questionnaires were only sent once to participants in both rounds, it was implicitly assumed that the responses would be the same after two years. Secondly, no other symptoms other than rectal bleeding were considered. In the third place, the questionnaire investigated the existence of relatives with three types of cancer, allowing the screening of individuals with family history without taking into account that the risk of CRC varies according to age at diagnosis, type of relative, and number of relatives affected. These data suggest that the characteristics of our questionnaire probably allowed the screening of individuals with a greater risk of developing colorectal disease. In fact, and as a result of the findings of this study, we have modified the questionnaire to be sent to the candidate individuals in coming rounds. In addition to rectal bleeding, the presence of other symptoms in the previous 3-6 months will be evaluated, such as changes in bowel habit, abdominal pain and anaemia due to iron depletion. In terms of family history, the number, age and the degree of relationship of family members with CRC will be investigated. Depending on the response, we will exclude non-candidates from the screening programme and refer them to more specific measures.

The complexity involved in the development of screening programmes in CRC in large populations compels us to ascertain all the factors into which the population may be grouped for different types of screening or age of onset according to the risk of developing the disease. Among these factors, mention may be made of the higher incidence of CRC in males and at an earlier age (29), and the greater risk in the presence of a history of CRC in first-degree relatives $(27,28,30)$. These results may therefore have important implications for the offer of CRC screening programmes and their optimisation in terms of cost effectiveness (31).

In summary, CRC population screening programmes should be offered to eligible individuals using appropriate instruments that make it possible to adapt the type of screening to the risk of individuals to be screened. The 
questionnaires must be easy to interpret by the population and the data that may constitute grounds for exclusion collected. Moreover, the questionnaires should be read by trained personnel and, in cases of exclusion due to symptoms or family history of CRC, there should be the possibility of specific screening. The introduction of people with a higher risk, besides offering an unsuitable test for these population groups, could alter the results expected in this type of screening.

\section{REFERENCES}

1. Advisory Committee on Cancer Prevention. Recommendations on cancer screening in the European Union. Eur J Cancer 2000; 36: 1473-8.

2. Johns LE, Houlston RS. A systematic review and meta-analysis of familial colorectal cancer risk. Am J Gastroenterology 2001; 96: 2992-03.

3. Selvachandran SN, Hodder RJ, Ballal MS, Jones P, Cade D. Prediction of colorectal cancer by a patient consultation questionnaire and scoring system: a prospective study. Lancet 2002; 360: 278-83.

4. Sharan R, Schoen RE. Cancer in inflammatory bowel disease. An evidence-based analysis and guide for physicians and patients. Gastroenterol Clin North Am 2002; 31: 237-54.

5. Vasen H, Möslein G, Alonso A, Bernstein I, Bertario L, Blanco I, et al. European guidelines for the clinical management of Lynch syndrome (HNPCC). J Med Genet 2007; 44: 353-62.

6. Levin B, Lieberman DA, McFarland B, Smith RA, Brooks D, Andrews KS, et al. Screening and surveillance for the early detection of colorectal cancer and adenomatous polyps, 2008: a joint guideline from the American Cancer Society, the US Multi-Society Task Force on Colorectal Cancer, the American College of Radiology. CA Cancer J Clin 2008; 58: 130-60.

7. Peris M, Espinàs JA, Muñoz L, Navarro M, Binefa G, Borràs JM. Lessons learned from a population-based pilot programme for colorectal cancer screening in Catalonia (Spain). J Med Screening 2007; 14: 81-6.

8. Jass JR, Sobin LH. Histological typing of intestinal tumors. 2nd ed. Heidelberg: Springer-Verlag; 1989.

9. Navarro M, Peris M, Binefa G, Nogueira JM, Miquel JM, Espinás JA, et al. Hallazgos colonoscópicos del estudio piloto de cribado de cáncer colorrectal realizado en Cataluña. Rev Esp Enferm Dig 2008; 100: 343-8.

10. Winawer S, Fletcher R, Rex D, Bond J, Burt R, Ferrucci J, et al. Gastrointestinal Consortium Panel. Colorectal cancer screening and surveillance: clinical guidelines and rationale. Update based on new evidence. Gastroenterology 2003; 124: 544-60.

11. Towler B, Irwig L, Glasziou P, Kewenter J, Weller D, Silagy C. A systematic review of the effects of screening for colorectal cancer using faecal occult blood test, Hemoccult. BMJ 1998; 317: 559-65.

12. Richards C, Klabunde C, O'Malley M. Physicians' recommendations for colon cancer screening in women. Too much of a good thing? Am J Prev Med 1998; 15: 246-9.
13. Fisher D, Judd L, Sanford N. Inappropriate colorectal cancer screening: findings and implications. Am J Gastroenterol 2005; 100: 252630 .

14. Korsgaard M, Pedersen L, Sørensen HT, Laurberg S. Reported symptoms, diagnostic delay and stage of colorectal cancer: a population-based study in Denmark. Colorectal Dis 2006; 8: 688-95.

15. Carlsson L, Hajansson A, Nordenskjold B. Common cancer-related symptoms among GP patients. Opportunistic screening in primary health care. Scand J Primary Health Care 2001; 19: 99-103.

16. Lawrenson R, Logie J, Marks C. Risk of colorectal cancer in general practice patients presenting with rectal bleeding, change in bowel habit or anaemia. Eur J Cancer Care 2006; 15: 267-71.

17. Thompson MR, Ellis BG, Swarbrick ET, Swarbrick ET, Wood LF, Atkin WS. Identifying and managing patients at low risk of bowel cancer in general practice. Br Med J 2003; 327: 263-5.

18. Hamilton W, Round A, Sharp D, Peters TJ. Clinical features of colorectal cancer before diagnosed: a population-based case-control study. Br J Cancer 2005; 93: 399-405.

19. Du Toit J, Hamilton W, Barraclough K. Risk in primary care of colorectal cancer from new onset rectal bleeding: 10 years prospective study. BMJ 2006; 333: 69-70.

20. Ferraris R, Senore C, Fracchia M, Sciallero S, Bonelli L, Atkin WS, et al. Predictive value of rectal bleeding for distal colonic neoplastic lesions in a screened population. Eur J Cancer 2004; 40: 245-52.

21. Ahmed S, Leslie A, Thaha MA, Carey FA, Steele RJ. Lower gastrointestinal symptoms are not predictive of colorectal neoplasia in a faecal occult blood screen-positive population. Br J Surg 2005; 92: $478-81$.

22. Knaebel HP, Kienle P. Patients at risk of familial colorectal cancer. Br Med J 2005; 331: 1033-4.

23. Dove-Edwin I, de Jong AE, Adams J, Mesher D, Lipton L, Sasieni P, et al. Prospective results of surveillance colonoscopy in dominant familial colorectal cancer with and without Lynch syndrome. Gastroenterology 2006; 130: 1995-2000.

24. Menges M, Fischinger J, Gärtner B, Georg T, Woerdehoff D, Maier $\mathrm{M}$, et al. Screening colonoscopy in 40- to 50-year-old first-degree relatives of patients with colorectal cancer is efficient: a controlled multicentre study. Int J Colorectal Dis 2006; 21: 301-7.

25. Smith RA, Cokkinides V, Eyre HJ. American Cancer Society guidelines for the early detection of cancer. CA Cancer J Clin 2006; 56: 11-25.

26. Burt RW. Colon cancer screening. Gastroenterology 2000; 119: 83753 .

27. Lindgren G, Liljegren A, Jaramillo E, Rubio C, Lindblom A. Adenoma prevalence and cancer risk in familial non-polyposis colorectal cancer. Gut 2002; 50: 228-34.

28. Bradshaw N, Holloway S, Penman I, Dunlop MG, Porteous ME. Colonoscopy surveillance of individuals at risk of familial colorectal cancer. Gut 2003; 52: 748-51.

29. Brenner H, Hoffmeister M, Arndt V, Haug U. Gender differences in colorectal cancer: implications for age at initiation of screening. Br J Cancer 2007; 96: 828-31.

30. Regula J, Rupinski M, Kraszewska E, Polkowski M, Pachlewski J, Orlowska J, et al. Colonoscopy in colorectal-cancer screening for detection of advanced neoplasia. N Eng J Med 2006; 355: 1863-72.

31. Shergill AK, Terdiman JP. Refining colorectal cancer screening recommendations based on gender. Gastroenterology 2007; 132: 260516. 